A N N A L E S Annales de Bretagne et des Pays de l'Ouest

\title{
Libraires et imprimeurs protestants de la France atlantique, $\mathrm{XVI}^{e}-\mathrm{XVII}{ }^{e}$ siècle
}

\section{François Brizay}

\section{OpenEdition}

Journals

Édition électronique

URL : https://journals.openedition.org/abpo/6909

DOI : $10.4000 /$ abpo.6909

ISSN : 2108-6443

\section{Éditeur}

Presses universitaires de Rennes

\section{Édition imprimée}

Date de publication : 30 juin 2021

Pagination : 213-214

ISBN : 978-2-7535-8359-7

ISSN : 0399-0826

\section{Référence électronique}

François Brizay, "Libraires et imprimeurs protestants de la France atlantique, $x v l^{e}-x v I^{e}$ siècle ", Annales de Bretagne et des Pays de l'Ouest [En ligne], 128-2 | 2021, mis en ligne le 30 juin 2020, consulté le 17 octobre 2022. URL : http://journals.openedition.org/abpo/6909 ; DOI : https://doi.org/10.4000/abpo. 6909 
nues, réelles et incessantes, in situ dans les carrières, les ports, les édifices, mais aussi aux archives, et de plus rédigé en synthèses accessibles, même aux non géologues que nous sommes le plus souvent.

Jean-Claude MEURET

Hoareau, Muriel, Poton de Xaintrailles, Didier, et Pairault, Louis-Gilles (dir.), Libraires et imprimeurs protestants de la France atlantique, XVI ${ }^{\ell}-X V I I^{e}$ siècle, Rennes, Presses Universitaires de Rennes, 2020, 176 p.

L'histoire de l'imprimerie française sous l'Ancien Régime a privilégié les grands centres d'édition qu'étaient Paris, Lyon et Rouen. Elle néglige parfois les régions situées dans l'Ouest du royaume, de la Basse-Normandie au Béarn, où les communautés protestantes ont développé des centres d'imprimerie dans des villes petites et moyennes comme La Rochelle, Saumur, Niort, Montauban, Sainte-Foy-la-Grande, Orthez ou Puylaurens.

Les neuf articles réunis par Muriel Hoareau, Didier Poton de Xaintrailles et Louis-Gilles Pairault sont des contributions qui ont été présentées pendant les journées d'études organisées les 9 et 10 novembre 2017 à La Rochelle par le Centre de Recherche en Histoire Internationale et Atlantique, à l'occasion de la commémoration du cinq-centième anniversaire de la Réforme protestante. La Rochelle ayant été un des pôles majeurs de la librairie et de l'imprimerie protestantes jusqu'en 1628, elle était le lieu idéal pour réunir des spécialistes de l'histoire du livre et du protestantisme dans la France atlantique (Didier Boisson, Jean-Claude Bonnin, Philippe Chareyre, Thomas Guillemin, Muriel Hoareau, Marielle Mouranche, Jean-Paul Pittion, Didier Poton de Xaintrailles, Éric Suire).

Cette étude souligne les caractéristiques de l'édition protestante dans l'Ouest de la France, où les imprimeries eurent une activité plus irrégulière que dans le reste du pays, voire intermittente. Elle souligne d'abord l'évolution du centre de gravité de la production imprimée protestante. Le cœur de l'imprimerie huguenote fut d'abord La Rochelle, pendant une trentaine d'années à partir de 1568, date à laquelle le port saintongeais devint la capitale du parti huguenot. Les presses rochelaises de Barthélemy Berton et de Jean Portau, et celles de la dynastie des Haultin, défendirent la Cause avec conviction. Ensuite, de 1600 environ à 1685, l'imprimerie saumuroise s'imposa au détriment de celle de La Rochelle.

Les auteurs des communications soulignent ensuite la vie itinérante des imprimeurs. Thomas Portau imprima pour la cause huguenote à Pons et à Niort avant de s'installer à Saumur en 1601 ; Pierre Haultin arriva à La Rochelle à la demande de Jeanne de Navarre après avoir vécu à Paris et à Lyon ; Jérôme Haultin séjourna plus de dix ans en Angleterre avant de s'installer à La Rochelle, et Denis Haultin partit à Montauban en 1589. Dans le Sud-Ouest, les ateliers d'imprimerie étaient mobiles et les entrepreneurs se déplaçaient constamment avec une presse et un à deux jeux de caractères.

Les logiques éditoriales furent en partie imposées par le contexte culturel. L'absence d'université et d'académie protestante à La Rochelle conduisit les imprimeurs à produire des livres destinés surtout à l'ensemble de la France et à l'exportation. En revanche, la présence de l'académie et du collège protestants à Saumur explique la réputation des imprimeurs huguenots de cette ville, dont les plus renommés travaillaient pour l'académie : Thomas Portau, Jean Lesnier, Isaac Desbordes, Henri Desbordes. De même, c'est la présence d'institutions scolaires et 
universitaires qui favorisa le développement de l'imprimerie en Béarn. Le collège protestant, transformé en académie en 1566, fut doté d'un statut d'université en 1583. Louis Rabier fut le premier imprimeur à demeure de l'académie, de 1583 à 1606, d'abord à Orthez jusqu'en 1591, puis à Lescar où fut déplacée l'institution.

L'étude de la production des imprimeurs protestants de l'Ouest permet de souligner l'identité protestante. Sur les livres offerts au XvII siècle par l'académie de Saumur pour le prix de piété, elle s'exprime dans le choix de l'ornement apposé sur la reliure (une formule en latin qui ne rappelle pas l'identité de l'organisateur du prix mais manifeste l'appartenance à l'institution académique). L'analyse des titres édités dans le Sud-Ouest montre que la littérature religieuse occupe la première place dans les lectures du XVII ${ }^{\mathrm{e}}$ siècle, et que plus on descend dans la hiérarchie sociale, plus la place de la religion est forte. Contrairement à une idée reçue, les lecteurs protestants possédaient peu de Bibles complètes, mais des psautiers, et leurs livrets se tournaient vers la pratique plutôt que vers la réflexion. Comme les protestants représentaient alors 5 à $10 \%$ de la population totale du Sud-Ouest, selon les régions, la part des textes protestants (plus de $15 \%$ de l'ensemble des imprimés religieux repérés) est surreprésentée pour deux raisons : le niveau socioculturel des fidèles et le prosélytisme des presses huguenotes, car dans les villes protestantes la religion fournit toujours au moins $50 \%$ des titres publiés, contre 33 à $42 \%$ dans les villes catholiques.

Les imprimeurs protestants publièrent des Bibles et des ouvrages de théologie, mais ils s'illustrèrent par la publication de pamphlets et d'ouvrages de controverse religieuse pour défendre la Cause, jusqu'à la fin de la période où l'Édit de Nantes resta en vigueur. Parmi la centaine de titres publiés chez vingt-deux imprimeurslibraires identifiés, dans huit villes du Sud-Ouest, et conservés dans les collections de l'ancienne bibliothèque de la faculté de théologie protestante de Montauban, la moitié des titres sont des thèses de l'académie protestante de Montauban, et pour le reste la théologie domine. Il s'agit principalement d'ouvrages de controverse, car jusqu'à la veille de la Révocation, des huguenots polémiquèrent avec leurs adversaires catholiques. Ainsi, pour répondre aux accusations portées par l'évêque d'Angers, Antoine Arnaud, et par Pierre Nicole, contre la morale des réformés, le pasteur de Saintes, Élie Merlat, fit publier en 1676 à Saumur une Réponse générale au livre de monsieur Arnaud, qui fut brûlée publiquement à Saintes le 9 juillet 1680 sur ordre du parlement de Guyenne.

Ce recueil d'actes de journées d'études rochelaises est un outil de travail appréciable. Il rend service aux chercheurs et aux lecteurs curieux qui s'intéressent à l'histoire du livre protestant français. Outre les communications, il est enrichi de 22 illustrations représentant notamment des couvertures de livres imprimés par des protestants, et il est complété par un supplément de 5 pages dans lequel Jean Flouret mentionne 29 titres publiés à La Rochelle entre 1629 et 1685, qu'il ajoute au Répertoire bibliographique des livres imprimés en France au XVe siècle, tome II, La Rochelle, Baden-Baden, Koerner, 1980.

François BRIZAY

Baumier, Béatrice, Calllou, François, Maillard, Christophe, et Petitrrère, Claude, Les élites urbaines sous l'Ancien Régime. L'exemple de Tours, Tours, Presses universitaires François-Rabelais, 2020, 429 p.

Quatre auteurs, acteurs essentiels de la recherche universitaire sur la ville de Tours à l'époque moderne depuis vingt ans, ont uni leurs forces et croisé leurs analyses pour nous offrir un très beau tableau des élites urbaines de cette grande ville 